\title{
Mining of Algal Lipids for the Production of Biofuel Using Oedogonium tyrolicum
}

\author{
KarukuvelRaja R $^{1}$, Rekha Shanmugam ${ }^{2}$, Sanjay Prasad S ${ }^{3}$, Dr. K. V. Shalini* ${ }^{4}$ \\ ${ }^{1,3}$ Genolites Research and Development Laboratory, Coimbatore-641035, TamilNadu, India. \\ email: genolitesrdl@gmail.com \\ ${ }^{2}$ Department of Biotechnology, PRIDE, Periyar university, Salem-636011, TamilNadu, India. \\ email: rekharey997@gmail.com \\ ${ }^{4}$ Assistant professor, Department of Biochemistry, Biotechnology and Bioinformatics, \\ Avinashilingam Institute for Home Science and Higher Education for Women, Coimbatore- \\ 641043, TamilNadu, India.email: shalini_bc@avinuty.ac.in (*Corresponding Author)
}

Address for correspondence

Dr. K. V. Shalini ,

email: shalini_bc@avinuty.ac.in 


\begin{abstract}
:
Fuel is the most significant need of the modern world but now the availability of fuel source has decreased alarmingly. Therefore, scientists are investigating the other alternative source as substitutes for fuel. Microalgae are considered as one of the best source for the fuel production because they are easily available, cheaper, easy to handle and eco-friendly. In this study, the Oedogonium tyrolicum was isolated from Sulur Lake. The isolated species were identified by morphological examination. It was cultivated for extraction of fatty acids by slight modification on Blight \& Dryer method. Fatty acid content from the isoted microalgae was found to be $16 \%$. Trans-esterification was carried out to the extracted fatty acids. Characterization of the biodiesel was done by UV Spectroscopy, FTIR and GCMS. In UV Spectroscopy analysis, the peak was observed at $275 \mathrm{~nm}$ which refers the presence of FAME in extracted biodiesel. Three functional groups corresponding to Carboxylic acid, Alkane (Methyl group) and Ester are identified using FT-IR analysis and there were 21 type of mono esters present in biodiesel. 69.54\% of FAME compounds were identified by GCMS analysis. These results conclude that Oedogonium tyrolicum can serve as a potential source for the biodiesel production. Thus Oedogonium tyrolicum can be used for large scale production of biofuels.
\end{abstract}

Keywords: Biofuel, Microalgae, FAME, Biodiesel, Oedogonium tyrolicum 


\section{Introduction:}

Over $80 \%$ of the world's annual global primary energy consumption to date is accounted for by fossil fuel (Coal, Crude oil, and natural gas), particularly in the areas of transportation, manufacturing and domestic heating. However, rapid depletion of fossil fuels reserves coupled with concerns over anthropogenic carbon dioxide $\left(\mathrm{CO}_{2}\right)$ equivalent emissions of greenhouse gases (GHG's), such as $\mathrm{CO}_{2}$, methane $\left(\mathrm{CH}_{4}\right)$ and nitrous oxide $\left(\mathrm{N}_{2} \mathrm{O}\right)$, arising from fossil fuel combustion has driven the world towards renewable sources of energy. Similarly, predictions by some industry sources and researchers that the world's fossil oil reserves would be exhausted in less than 50 years from now and frequent threats to the security of fossil fuel supply due to global political developments limit fossil fuel dependency. Conversely, others think that fossil fuels dominance will remain and in abundant supply well for a considerable period of time. This is with regards to the huge technological advancement, potential reserves, and the discoveries of latest unconventional reserves of natural gas (Kaloudas et al., 2021).

These scenarios have led to increased research interest in a portfolio of climate change effects mitigation options such as: new renewable sources for energy and transportation fuels, the deployment of more efficient fossil-fuel combustion technologies, increasing the efficiency of energy conversion and utilisation, switching to low carbon content fuels and Carbon Capture and Storage (CCS) of $\mathrm{CO}_{2}$ from fossil-fuel power plants. In addition, vigorous long-term research aimed at developing advanced and potentially viable model concept of utilising waste $\mathrm{CO}_{2}$ from power plants as an economic advantage through processes that can profitably utilise captured $\mathrm{CO}_{2}$ is necessary (Kröger and Müller-Langer, 2012).

Microalgae biodiesel production is an emerging field that has attracted a lot of attention as a result of its potential for sequestering power plants waste $\mathrm{CO}_{2}$ (with supplementary nutrients) into biomass at a higher photosynthetic rate $\left(1.83 \mathrm{~kg}\right.$ of $\mathrm{CO}_{2}$ is required to produce $1 \mathrm{~kg}$ of dry algal biomass), far higher than that of dedicated energy food and oil crops. Microalgae can be cultivated all year round giving higher yields than the best oilseed crop (rapeseed). For example, microalgae biodiesel yields $12,000 \mathrm{~L} \mathrm{ha}^{-1}$ (open pond production) compared to1,190 $\mathrm{L} \mathrm{ha}^{-1}$ for rapeseed. Also, its capacity to utilise nutrients particularly Nitrogen $(\mathrm{N})$ and Phosphorous $(\mathrm{P})$ from a variety of wastewater, sets it apart from other biomass resources. In addition, the biochemical configuration algal biomass could be readily modified via altering culture environment with significantly enhanced lipid synthesis (Kothari et al., 2021). 
Furthermore, microalgae are a major source of high value co-products such as proteins (beta-carotene) extracted from Dunaliella and Spirulina and residual biomass, which are widely useful as animal feed stocks and a source of fertilizer. These outlined microalgal connected benefits for power plants waste $\mathrm{CO}_{2}$ utilisation, bioremediation of wastewater and its potential for biofuel production justifies the need for extended research and development effort in microalgae biofuel technology (Voloshin et al., 2016).

However, in spite of its huge potentials, microalgae biomass cultivation process, incorporation of production system for power plants waste flue gas utilisation, gas transfer and mixing, wastewater utilisation options, algal harvesting and oil extraction, and biomass conversion techniques have many challenges which limit the development of microalgae biofuel technology. As a result, these processes require specific enquiry to allow for commercial full-scale production and viable utilisation of microalgal biomass for biofuel processing (Kumar et al., 2020). Hence, an attempt was made to study the lipid content and biofuel generation from Oedogonium tyrolicum. The present study concentrates on the extraction of biofuel from the Oedogonium tyrolicum. The microalgae were isolated and cultivated. The lipids and fatty acids were extracted and converted to biofuel by the process of transesterification. The extracted biofuel was characterized by UV-Vis spectroscopy, FTIR and GC-MS analysis.

\section{Materials and Methods}

\section{Collection of sample}

The algal sample was collected from Sulur Lake, Coimbatore, Tamil Nadu and India. Then the sample was stored at $4^{\circ} \mathrm{C}$. (Figure-1)

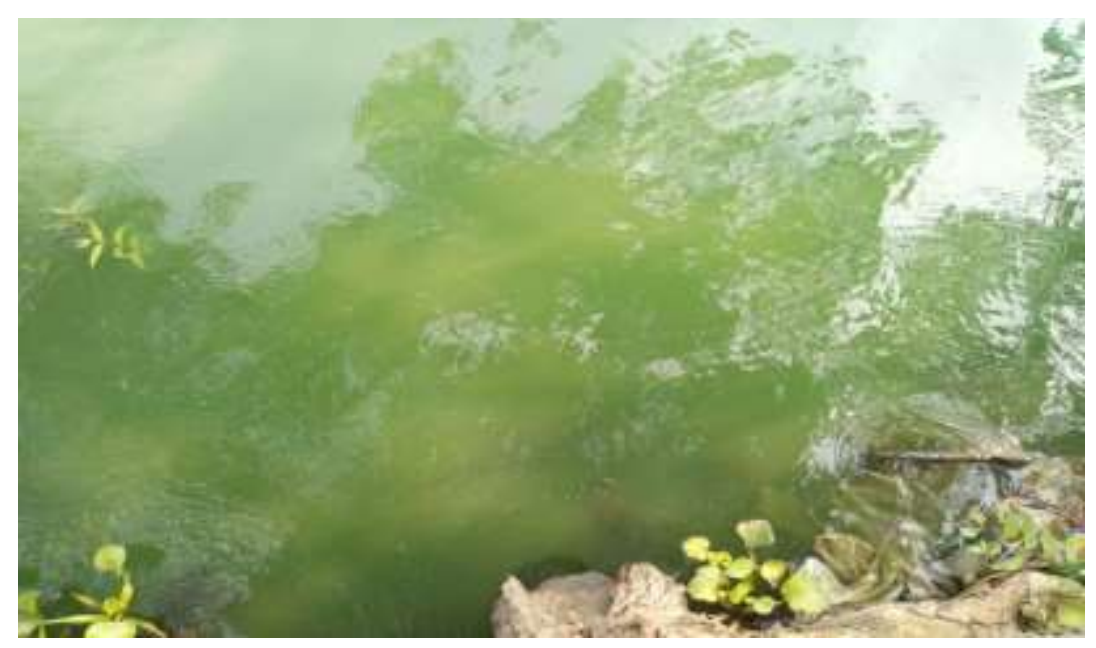

Figure-1: Sample collection site 


\section{Isolation of micro algae}

Collected sample was examined under microscope for confirmation of presence of micro algae. Then the sample was serially diluted and inoculated in BG 11 media. They are incubated at $20^{\circ} \mathrm{C}$ for 15 days.

\section{Microscopic characterization of isolated algae}

Cultured algal sample was examined under microscope for the identification algae based on its morphology.

\section{Mass production of isolated algal bio mass}

Selected algae was purified and cultivated in 5 liters of BG11 media for the bio mass. After cultivation, the bio mass was collected by the centrifugation. Collected bio mass was dried under $105^{\circ} \mathrm{C}$ for $1 \mathrm{hr}$.

\section{Extraction of lipid by Bligh and Dyer (1959)}

A 15-ml glass vial containing $20 \mathrm{~g}$ algal biomass in which $100 \mathrm{ml}$ methanol and $50 \mathrm{ml}$ chloroform were added and kept for $24 \mathrm{~h}$ at $25^{\circ} \mathrm{C}$. The mixture was agitated in a vortex for 2 min. $50 \mathrm{ml}$ of chloroform was again added and the mixture was shaken vigorously for $1 \mathrm{~min}$. (fig.2). After, $50 \mathrm{ml}$ of distilled water was added and the mixture was mixed in a vortex again for $2 \mathrm{~min}$. The layers were separated by separating funnel. The lower layer was collected into a previously weighed clean vial (W1). Evaporation was carried on in a water bath and the residue was further dried at $104^{\circ} \mathrm{C}$ for $30 \mathrm{~min}$. The weight of the vial was again recorded (W2). Lipid content was calculated by subtracting W1 from W2, and was expressed as \% DCW.

\section{Transesterification process}

$0.5 \mathrm{~g}$ of $\mathrm{NaOH}$ pellets were crushed with methanol and then Stirring for 5-10 min until the $\mathrm{NaOH}$ pellets were dissolved. Measure out $60 \mathrm{ml}$ of the algal oil. Add all the contents to the reaction flask. Heat the flask contents to $50 \mathrm{c}^{\circ}$ for $20 \mathrm{~min}$. with continuous stirring. While still warm, pour the mixture into a separating funnel and allow cooling until the mixture separates into two layers. The upper layer is biodiesel while the lower is glycerol. Don't let it stand for too long as the lower layer may solidify. 


\section{Characterization of Biodiesel}

\section{UV Spectroscopy Analysis}

The biodiesel was initially analysed in UV spectroscopy. The biodiesel contains FAME that can read at 245-305 $\mathrm{nm}$.

\section{FTIR Analysis}

FTIR analysis used for identification of functional group presence in the biodiesel. Mainly focused on Carboxylic group and methyl esters.

\section{Gas Chromatography - Mass Spectroscopy}

Fatty acid composition was estimated by GC analysis. The sample was tested in SITRA, Coimbatore.

Equipment: THERMO GC - TRACE ULTRA VER: 5.0,

Thermo Ms DSQ Ii Column: DB 35 - MS CAPILLARY STANDARD NON POLAR

Column Dimension: 30 Mts, ID: 0.25 mm, FILM: $0.25 \mu \mathrm{m}$

Carrier Gas : $\mathrm{He}$

Flow: 1.0 ML/Min

Temp Prog: OVEN TEMP $70^{\circ} \mathrm{C}$ RAISED TO $260^{\circ} \mathrm{C}$ AT $6 \mathrm{C} / \mathrm{MIN}$ 


\section{Result and Discussion}

\section{Isolation and Authentication}

The microscopic images of the isolated microalgae were shown in the Figure-2. It was observed to be filamentous and cell division occurs near septum and apical cap (folded structure near the septum); cell body cylindrical, laterally straight or wavy or swell at one end of the cell body in some species; chloroplast reticulated with many pyrenoids. Therefore, the isolated microalgae was identified to be Oedogonium tyrolicum.
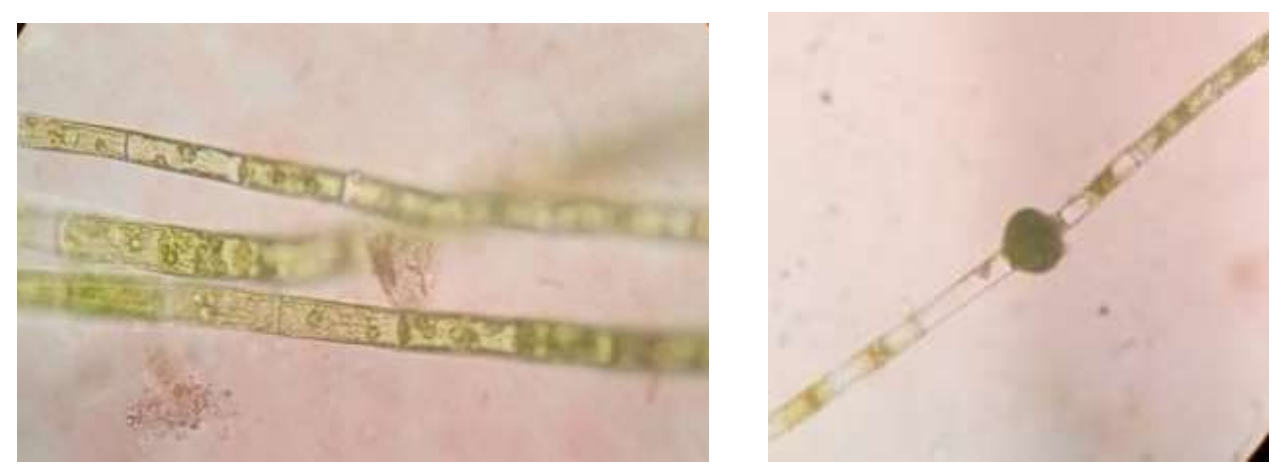

Figure-2: Microscopic observation of isolated microalgae

\section{Microalgae Harvesting}

The microalgae cells were harvested using a Beckman Avanti J-251 high speed centrifuge (Beckman Coulter, chaska, MN, USA) at $8000 \mathrm{rpm}$ for $10 \mathrm{~min}$. The samples were then transferred to pre-weighed Petri dishes. In order to determine the dry weight of the algal sample, the resulting biomasses were freeze dried. The dry weight of microalgae (Mdw) in milligrams was found to be $1.2 \mathrm{gm}$ for $100 \mathrm{ml}$ (Figure-3).

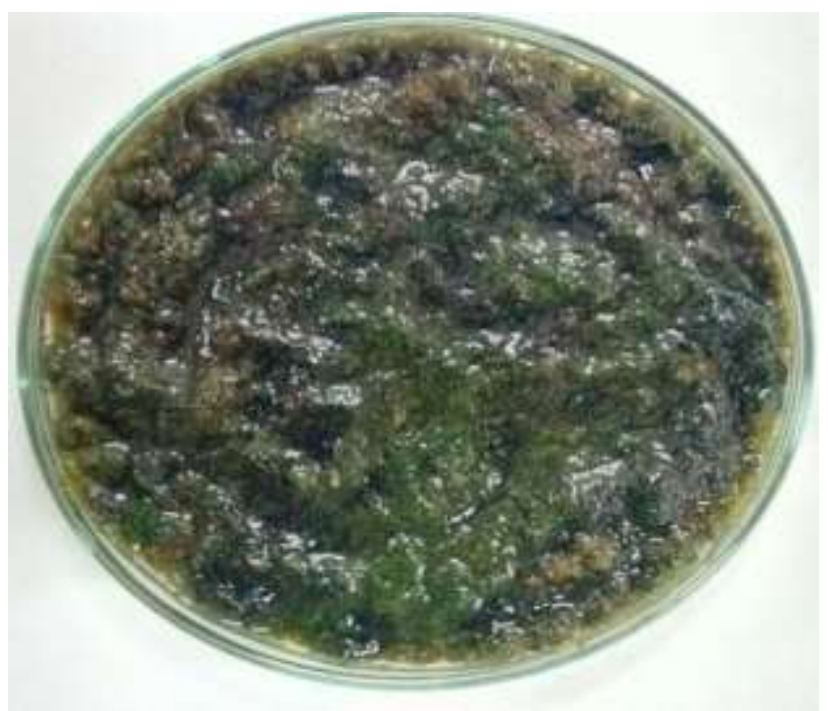

Figure-3: Biomass extraction 


\section{Extraction of lipid}

\section{Lipid Extraction}

The Folch method for lipid extraction was used in this work. The solution volume was 20 times greater than the volume of biomass in order to obtain an adequate volume to continue the experimental analysis. The mixture was then shaken for 20 min using a Bioline BL4600 orbital shaker at $150 \mathrm{rpm}$. The solution containing chloroform-methanol and lipid was separated from the biomass by gravity filtration using Machery-Nagel 615MN filter papers.

This solution was collected in centrifuge tubes and then the lipid was rinsed in the test tube by chloroform to minimize lipid losses. These tubes were re-filled by volume of Milli-Q water equal to $20 \%$ of the total volume of the sample. To separate the chloroform-methanol phase, the samples were centrifuged at $3000 \mathrm{rpm}$ for $10 \mathrm{~min}$. The upper phase was discarded by siphoning using a Pasture pipette and the lower phase containing lipids was evaporated under vacuum in a rotary evaporator. The samples were dried and left at the room temperature for one day for further drying, then weighed to determine the lipid content (Figure-4 and 5).

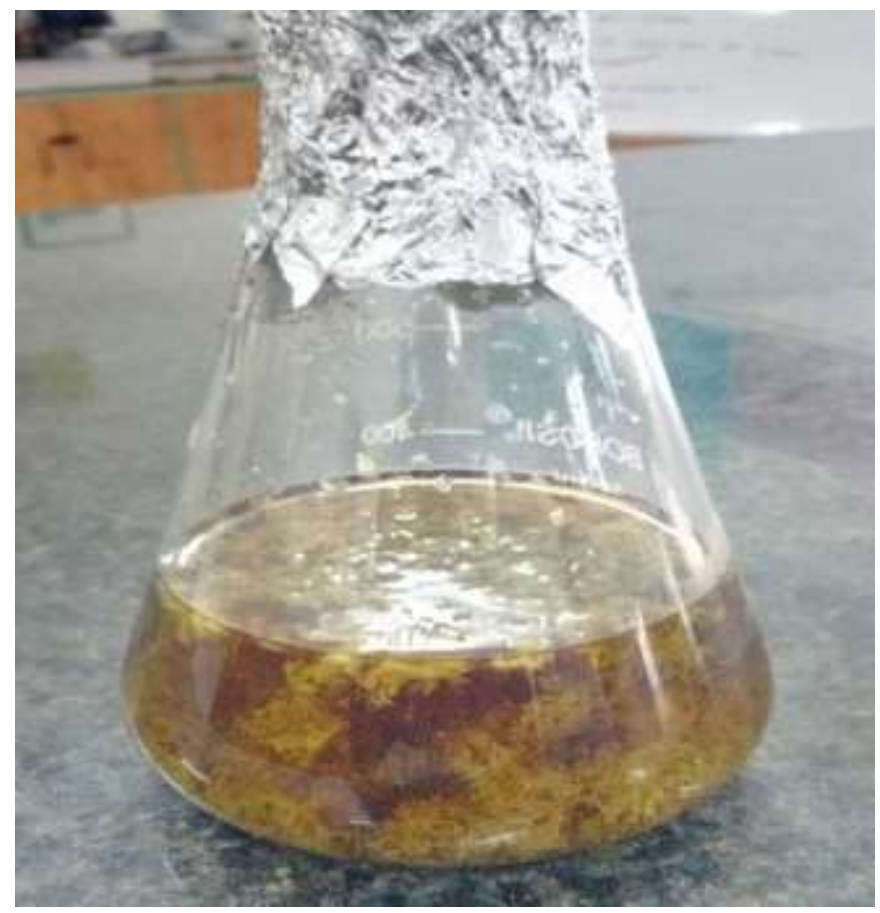

Figure-4: Flask containing biomass in methanol:chloroform 


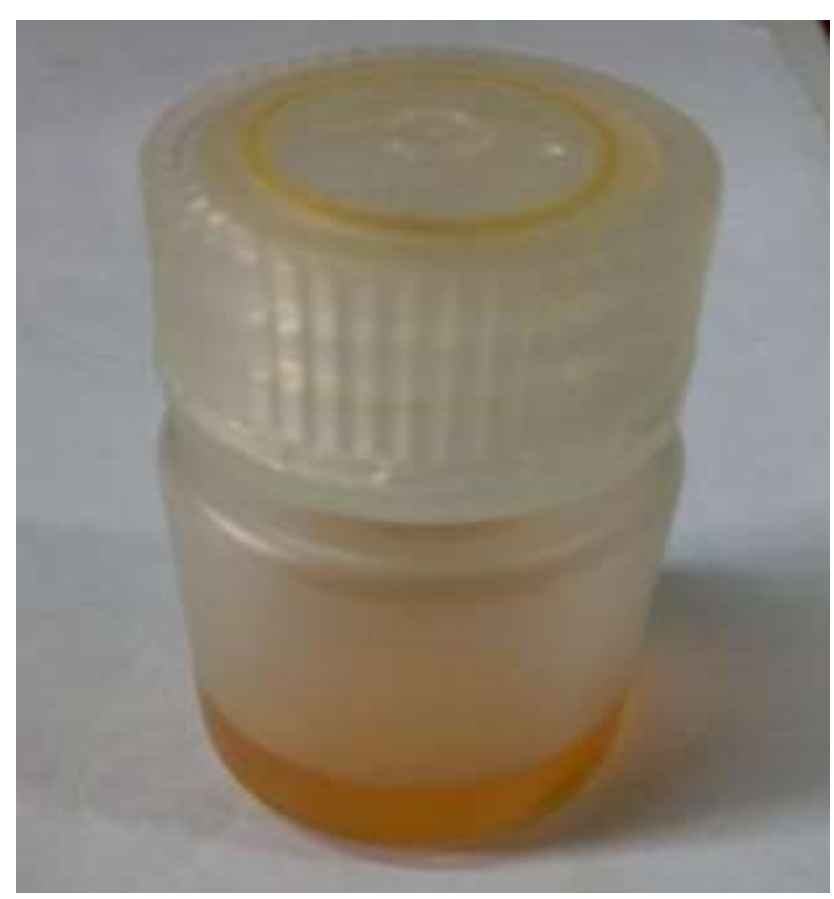

Figure-5: Trans-esterification

\section{Chareterization of Biodiesel}

\section{UV-Spectroscopy Analysis}

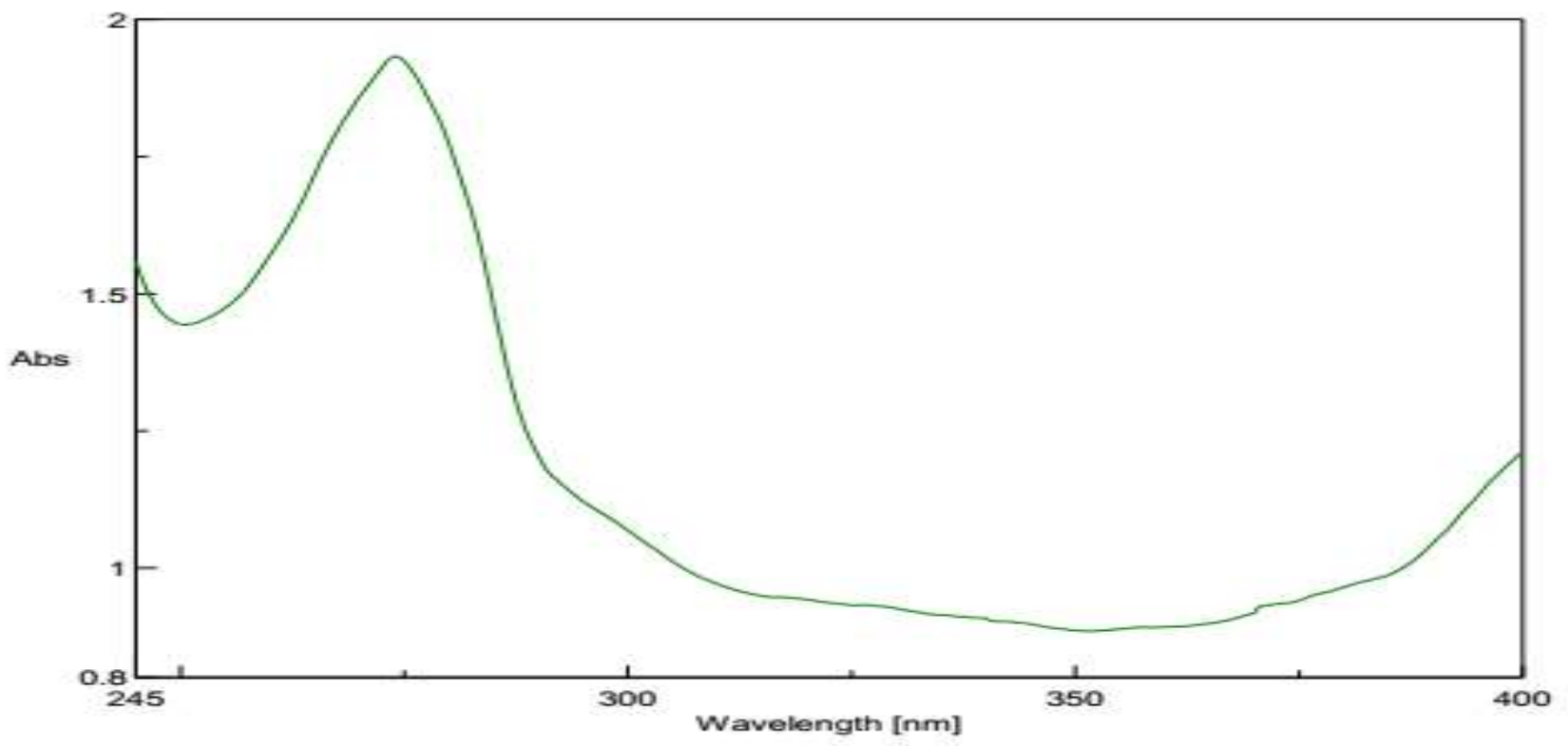

Figure-6: UV-Spectroscopy Analysis 
The extracted and transesterified biofuel was studied under UV spectrophotometer at different wavelength such as $245 \mathrm{~nm}, 300 \mathrm{~nm}, 350 \mathrm{~nm}$ and $400 \mathrm{~nm}$. The absorbance was high in the wavelength of $275 \mathrm{~nm}$ indicating the presence of FAME (Figure-6).

\section{FTIR Analysis}

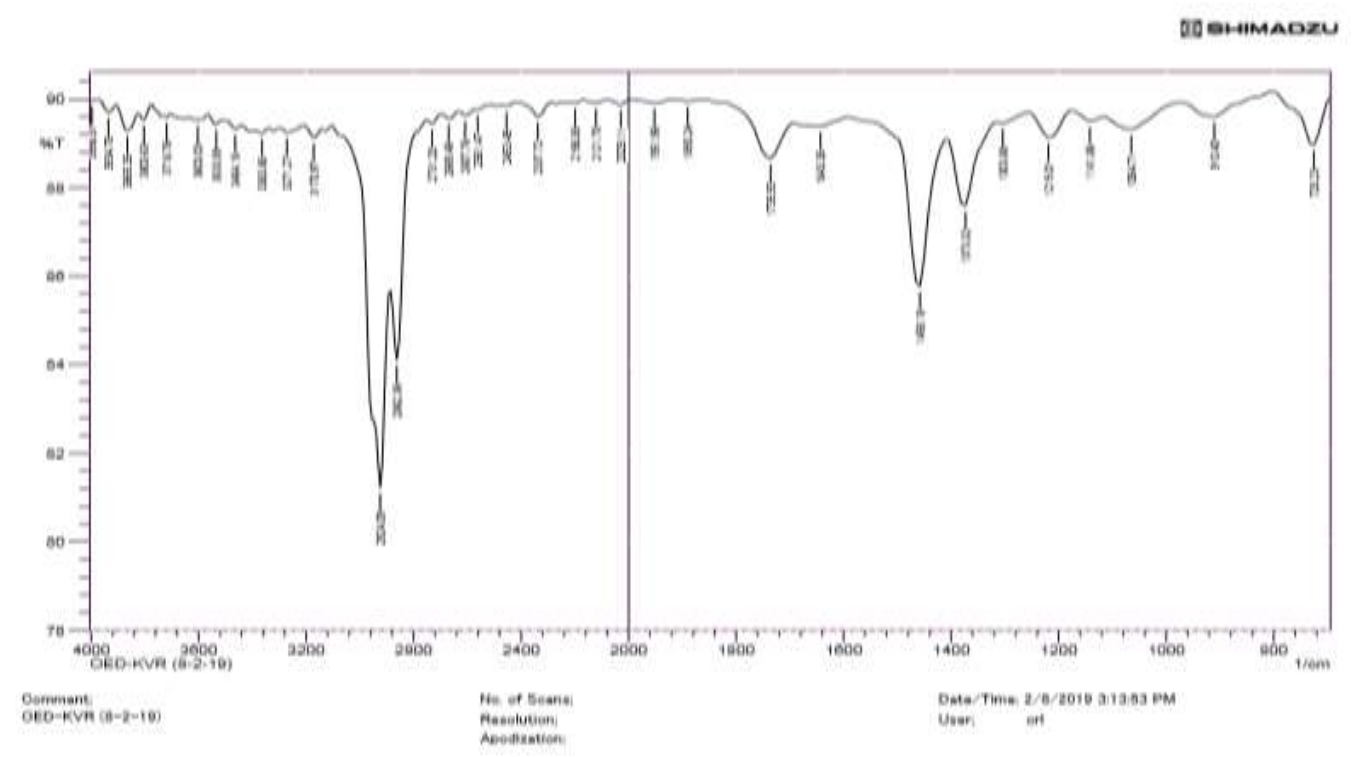

Figure-7: FTIR Analysis

Table-1: Functional groups presence in the biofuel

\begin{tabular}{|c|c|c|}
\hline S.NO & Peak cm $^{-1}$ & Functional group \\
\hline 1 & 3271.27 & Carboxylic acid \\
\hline 2 & 3170.91 & Carboxylic acid \\
\hline 3 & 1735.93 & lipids \\
\hline 4 & 1458.18 & Alkane (Methyl group) \\
\hline 5 & 1373.32 & lipids \\
\hline
\end{tabular}

FTIR analysis showed presence of several functional groups present in the biofuel.

Figure-7 and Table-1 shows the functional group analysis of biofuel. Presence of carboxylic acid and alkane with methyl group confirms the tested sample is biodiesel. 


\section{Gas Chromatography - Mass Spectroscopy Analysis}

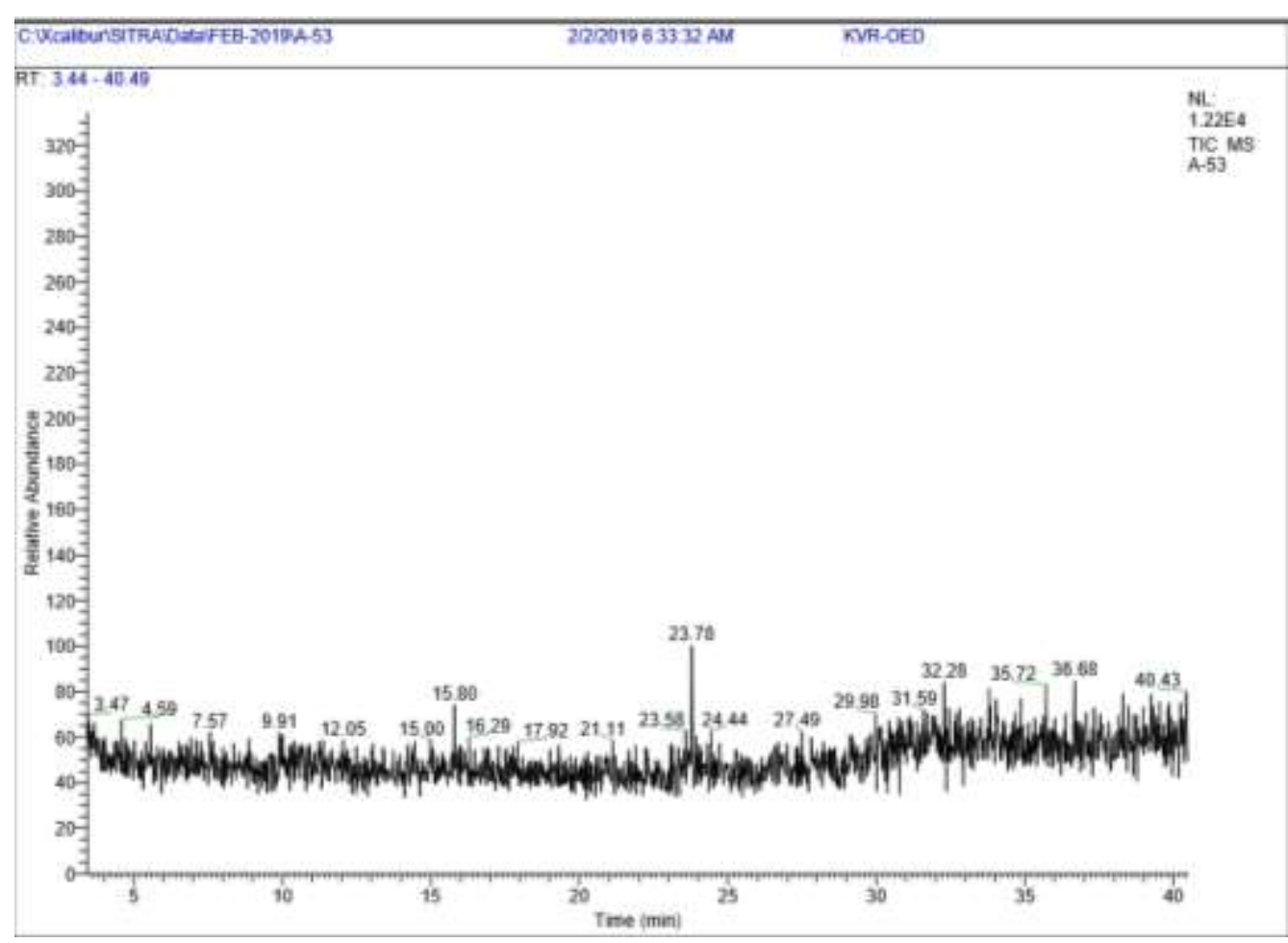

Figure-8: GC-MS Analysis

The biofuel was subjected to GC-MS analysis for identification of compounds present in the sample. Chromatogram shows the peaks of different compounds presence in the biodiesel (Figure-8). Totally 21 esters are present in this sample and approximately $69.54 \%$ of FAME in the biofuel. They are shown in the Table-2. 
Table-2: FAMEs present in the biofuel

\begin{tabular}{|c|c|c|c|}
\hline S. No & COMPOUNDS NAME & AREA \% & CMPD \% \\
\hline 1 & $\begin{array}{l}\text { Cyclohexane, (1-hexadecylheptadecyl)- } \\
\text { (CAS) }\end{array}$ & 1.76 & 2.53 \\
\hline 2 & $\begin{array}{l}\text { 15(1)-Hydroxypurpurin-7 Lactone } \\
\text { Dimethyl Ester }\end{array}$ & 3.41 & 4.9 \\
\hline 3 & 1-Octene, 2-methyl- (CAS) & 1.91 & 2.74 \\
\hline 4 & $\begin{array}{l}\text { 3-[4-(2-Methoxy-ethoxymethoxy)- } \\
\text { phenyl]-acrylic acid }\end{array}$ & 2.36 & 3.39 \\
\hline 5 & 2,2'-DIOXOSPIRILLOXANTHIN & 1.6 & 2.3 \\
\hline 6 & $\begin{array}{c}\text { TRIDEUTERIOMETHYL 10-EPOXY- } \\
\text { 7-ETHYL-3,11-DIMETHYLTRIDECA- } \\
\text { 2, 6-DIENOATE }\end{array}$ & 6.38 & 9.17 \\
\hline 7 & $\begin{array}{c}\text { 2-(5-CHLORO-2- } \\
\text { METHOXYPHENYL)PYRROLIDI NE }\end{array}$ & 7.18 & 10.32 \\
\hline 8 & Octadecane, 3-ethyl-5-(2-ethylbutyl)- & 1.74 & 2.5 \\
\hline 9 & Dodecanoic acid, ethenyl ester (CAS) & 3.05 & 4.38 \\
\hline 10 & $\begin{array}{c}\text { Docosanoic acid, 8,9,13-trihydroxy-, } \\
\text { methyl ester (CAS) }\end{array}$ & 1.71 & 2.45 \\
\hline 11 & Dodecanoic acid, tetradecyl ester & 2.80 & 4.02 \\
\hline 12 & $\begin{array}{l}\text { 3-Methoxymethyl-1-trimethylsilylhept-1- } \\
\text { yn-3-ol }\end{array}$ & 5.82 & 8.32 \\
\hline 13 & Octadecane, 3-ethyl-5-(2-ethylbutyl)- & 1.96 & 2.81 \\
\hline 14 & Docosane (CAS) & 2.81 & 4.04 \\
\hline 15 & Dodecanoic acid, but-3-enyl ester & 2.79 & 4.01 \\
\hline 16 & Dodecanoyl chloride (CAS) & 3.37 & 4.84 \\
\hline 17 & 4-Nitrophenyl laurate & 2.71 & 3.89 \\
\hline 18 & Dodecanoyl chloride (CAS) & 4.01 & 5.76 \\
\hline 19 & $\begin{array}{c}\text { 1,3,5-Triazin-2(1H)-one, } 4,6- \\
\text { bis(ethylamino)- }(\mathrm{CAS})\end{array}$ & 4.47 & 6.42 \\
\hline 20 & 1,3-O-Benzylidene glyceryl-2-myristate & 2.39 & 3.43 \\
\hline 21 & Lauric anhydride & 5.82 & 8.32 \\
\hline
\end{tabular}

\section{Discussion:}

The Algae are very huge and diverse autotrophic organisms, ranging from unicellular to multicellular forms. They affect water properties such as water colour, odour, taste, and the chemical composition, which may cause potential hazards for human and animal health. They are highly sensitive to the changes in their environment. Shift in algal species and population can be used to identify the environmental changes and the status of nutrient content. Algae are very good biological indications for water pollution assessment. Therefore, they have 
long been used to assess the quality of waters in lakes, ponds, reservoirs, rivers, and so on. However, identification of algae at their taxonomy level and the application in environmental assessment is a difficult process. Several studies reported the conventional identification of algae by using microscopy images, which is easy in the laboratory level (Anto et al., 2020).

Nutrient-rich waters can contain many thousands of planktonic (floating/suspended) algae cells per $\mathrm{ml}$ of water. A small vial of water was taken from near the surface provides plenty of material for microscope analysis. A vial $(5 \mathrm{ml})$ sample was collected from Sulur Lake, Coimbatore and algae was serially diluted and plated on BG-11 agar medium. The growth of the culture was measured using two different methods. The first method was using a Neubauer haemocytometer and light microscopy to measure the cell density. The UV/Vis spectrophotometer was used to monitor the growth curve by measuring the optical density (OD) of the culture at $515 \mathrm{~nm}$. This wavelength was selected based on preliminary tests for measuring the maximum absorbance at wide range of wavelengths. The OD is a simple and efficient method for measuring the growth curve (Chen and Lee, 2019).

The Folch method for lipid extraction was used in this work. Each sample of dried microalgae was mixed with a solution of (2:1) chloroform and methanol (analytical grade, Ajax Chemicals, Victoria, Australia). Widjaja et al. used chloroform and methanol $(2: 1, v / v)$ to extract the oil from microalgae. Biodiesel production from microalgae can be done using several well-known industrial processes, the most common of which is base catalyzed transesterification with alcohol. The transesterification is the reversible reaction of fat or oil (which is composed of triglyceride) with an alcohol to form fatty acid alkyl ester and glycerol. Stoichio-metrically, the reaction requires a 3:1 molar alcohol to oil ratio, but excess alcohol is (usually methyl alcohol is used) added to drive the equilibrium toward the product side. The reaction occurs stepwise: triglycerides are first converted to diglycerides, then to monoglycerides and finally to glycerol. Transesterfication can be catalyzed by acids, alkalis and lipase enzymes. However enzyme catalysts are rarely used as they are less effective. The alkali-catalyzed transesterification is about 4000 times faster than the acid catalyzed reaction. Consequently, alkalis such as sodium and potassium hydroxide are commonly used as commercial catalysts at a concentration of about $1 \%$ by weight of oil (Behera et al., 2015).

Alkali-catalyzed transesterification is carried out at approximately $60^{\circ} \mathrm{C}$ under atmospheric pressure, as methanol boils off at $65^{\circ} \mathrm{C}$ at atmospheric pressure. Under these conditions, reaction takes about 90 min to complete. A higher temperature can be used in combination with higher pressure. Methanol and oil do not mix; hence the reaction mixture 
contains two liquid phases. Other alcohols can be used, but methanol is the least expensive. To prevent yield loss due to saponification reactions (soap formation), the oil and alcohol must be dry and the oil should have a minimum of free fatty acids. Biodiesel is recovered by repeated washing with water to remove glycerol and methanol. This process of biodiesel production is found to be most efficient and least corrosive of all the processes as the reaction rate is reasonably high even at a low temperature of $60^{\circ} \mathrm{C}$ (Stephenson et al., 2011).

Fatty acid profiles of microalgal lipids are different among different algal species. In general, microalgal lipids contain fatty acids that possess two unique signatures of relatively longer chain length and high unsaturation. Microalgae have a common FA chain length from $\mathrm{C} 12$ to $\mathrm{C} 22$, which is a crossover with typical vegetable oil FA ranges of C14 to C20 and polyunsaturated FA range of C20 to C22. Lipid composition of S. limacinum presents most of the fatty acids (C14, C16 and C18) in typical vegetable oils but with a higher portion of polyunsaturated fatty acids. C16:0 is the most abundant saturated FA in S. limacinum lipids, and C22:6 are the highest among the polyunsaturated fatty acids. FA profile can directly affect derived fuel properties. The longer chain length and higher saturation of a FA leads to a higher viscosity of the corresponding FAME. Therefore, the combination of the long chain and the level of unsaturation in FAs would decide the viscosity of a microalgal biodiesel (Chen et al., 2019).

However, the unsaturated FA is a concern due to their susceptibility to oxidation. Besides, microalgal lipids used in this study contain even more polyunsaturated fatty acids (approximately 50\%) than those found in typical vegetable oils (typically in the range of $15 \%-35 \%$ ), thus the algal biodiesel made from such lipids tends to be oxidatively unstable. Fortunately, cold flow and oxidative stability are two interacting factors controlled by the chain length and the level of unsaturation of FAs. Long-chain saturated FAs cause poor clod flow property of corresponding biodiesel but promise a decent oxidative stability property. Polyunsaturated FAs are more reactive than saturated FAs due to the carbon-carbon double bonds that are easily to open up and react with alcohols. In contrast, a good portion of microalgal lipids is polyunsaturated which counter balances the poor cold flow property caused by the longer chain Fas (Shuba and Kifle, 2018). FTIR analysis showed the functional groups present in the synthesized biodiesel, Further GC-MS analysis showed the presence of various FAME compounds which are responsible for the biofuel production.

\section{Conclusion}

Oedogonium tyrolicum were isolated from Sulur Lake. The isolated species were characterized by morphological identification. Then it was cultivated in higher level for 
extraction of fatty acids. $16 \%$ of fatty acid were obtained from Oscillatoria tyrolicum. Trans esterification was done for the extracted fatty acids. Characterization of the biodiesel was done by UV Spectroscopy, FTIR and GCMS. In UV Spectroscopy the peak was observed at $275 \mathrm{~nm}$ which refers the presence of FAME in biodiesel. Three functional groups corresponding to Carboxylic acid, Alkane (Methyl group) and Ester were identified using FTIR analysis and there were totally 21 type of mono esters present in biodiesel. Through the GCMS $69.54 \%$ of FAME compounds present in the biodiesel. These results show the Oedogonium tyrolicum, was wonderful source for biodiesel production. 


\section{References}

Anto, S., Mukherjee, S.S., Muthappa, R., Mathimani, T., Deviram, G., Kumar, S.S., Verma, T.N., Pugazhendhi, A., 2020. Algae as green energy reserve: Technological outlook on biofuel production. Chemosphere

242. https://doi.org/10.1016/j.chemosphere.2019.125079

Behera, S., Singh, R., Arora, R., Sharma, N.K., Shukla, M., Kumar, S., 2015. Scope of Algae as Third Generation Biofuels. Front. Bioeng. Biotechnol. 2. https://doi.org/10.3389/fbioe.2014.00090

Chen, H., Li, T., Wang, Q., 2019. Ten years of algal biofuel and bioproducts: gains and pains. Planta. https://doi.org/10.1007/s00425-018-3066-8

Chen, Z., Lee, W.G., 2019. Electroporation for microalgal biofuels: A review. Sustain. Energy Fuels. https://doi.org/10.1039/c9se00087a

Kaloudas, D., Pavlova, N., Penchovsky, R., 2021. Lignocellulose, algal biomass, biofuels and biohydrogen: a review. Environ. Chem. Lett. https://doi.org/10.1007/s10311-021-01213$\mathrm{y}$

Kothari, R., Ahmad, S., Pathak, V. V., Pandey, A., Kumar, A., Shankarayan, R., Black, P.N., Tyagi, V. V., 2021. Algal-based biofuel generation through flue gas and wastewater utilization: a sustainable prospective approach. Biomass Convers. Biorefinery. https://doi.org/10.1007/s13399-019-00533-y

Kröger, M., Müller-Langer, F., 2012. Review on possible algal-biofuel production processes. Biofuels. https://doi.org/10.4155/bfs.12.14

Kumar, M., Sun, Y., Rathour, R., Pandey, A., Thakur, I.S., Tsang, D.C.W., 2020. Algae as potential feedstock for the production of biofuels and value-added products: Opportunities and challenges. Sci. Total Environ. https://doi.org/10.1016/j.scitotenv.2020.137116

Shuba, E.S., Kifle, D., 2018. Microalgae to biofuels: "Promising" alternative and renewable energy, review. Renew. Sustain. Energy Rev. https://doi.org/10.1016/j.rser.2017.08.042

Stephenson, P.G., Moore, C.M., Terry, M.J., Zubkov, M. V., Bibby, T.S., 2011. Improving photosynthesis for algal biofuels: Toward a green revolution. Trends Biotechnol. https://doi.org/10.1016/j.tibtech.2011.06.005

Voloshin, R.A., Rodionova, M. V., Zharmukhamedov, S.K., Nejat Veziroglu, T., Allakhverdiev, S.I., 2016. Review: Biofuel production from plant and algal biomass. Int. J. Hydrogen Energy. https://doi.org/10.1016/j.ijhydene.2016.07.084 